\title{
Analysis of PV Characteristics for Residential Application under Partial Shading Conditions
}

\author{
Byunggyu Yü ${ }^{1}$, Seok-Cheol Ko ${ }^{2}$ \\ ${ }^{1}$ Division of Electrical, Electronic and Control Engineering \& Regional-Industrial Application Research Institute \& Institute of IT \\ Convergence Technology, Kongju National University, Republic of Korea \\ ${ }^{2}$ Industry-University Cooperation Foundation Engineering \& Regional-Industrial Application Research Institute, \\ Kongju National University, Republic of Korea
}

ORCID: 0000-0001-5648-4268 (Byunggyu Yu)

\begin{abstract}
To prevent environmental pollution and foster new industries, the supply of new and renewable energy is widely spreading around the world. As the most representative renewable energy source, the proportion of PV generation in the power supply network is increasing. PV generation has been popularized for residential, commercial, and power plant purposes. Residential PV has been becoming more popular since its prices have been reduced with technological improvement. The output of PV system is highly dependent on environmental conditions like irradiance, temperature, and partial shading. Until now, the partial shading effect of residential PV system has not been analyzed based on the number of shading and shading strength. Thus, this paper presents the analysis of PV characteristics for residential application under partial shading conditions. PSIM simulation is used to summarize the shading effect of residential PV string. As a result, there are two local Maximum Power Point (MPP) under the same shading strength and the number of local MPP depends on the number of shading strengths for residential PV string.
\end{abstract}

Keywords: PV generation, Residential PV, Partial shading, PV string.

\section{INTRODUCTION}

Photovoltaic (PV) power generation is consisted of one or more PV modules combined with PV inverter that use energy from the sunlight to generate electricity [1]. PV systems can vary greatly in size from residential to massive utility scale PV plants [2-3]. Especially, residential PV has been becoming more popular since its prices have been reduced and its power is averaged around $5[\mathrm{~kW}$. For residential PV system, PV modules are generally connected in series as a single PV string [4-7].
The output of PV system is highly dependent on environmental conditions like irradiance, temperature, and partial shading [810]. Shading reduces the output of the whole string of PV modules and excess power from the unshaded power is dissipated in the shaded PV modules or cells [11-14]. Until now, the partial shading effect of residential PV system has been little analyzed based on the number of shading and shading strength. Thus, this paper presents the analysis of PV characteristics for residential application under partial shading conditions.

In this paper, design of residential PV system is firstly presented. Then, the simulation results under various partial shading scenarios are presented.

\section{CONFINGURATION OF RESIDENTIAL PV SYSTEM UNDER SHADING}

In this paper, residential PV power is designed as 2880 [W] and a commercial PV module is chosen as 360 [W]. The electrical specifications of the PV module are shown in Table 1. Based on the PV module specification, simulated PV modeling was presented as shown in Figure 1(a) and the simulation results under varying irradiance and temperature are presented as shown in Figure 1(b) and 1(c). According to this result, it is concluded that PV power is increased when the irradiance strength is high, or the temperature is low. The shading effect of PV modules is related with the irradiance. In this paper, the temperature condition is maintained to be fixed to consider shading effect of PV module because the temperature is fixed at a constant value during a short period of the day. For simplicity, it is assumed that single bypass diode is attached at the output of PV module. 


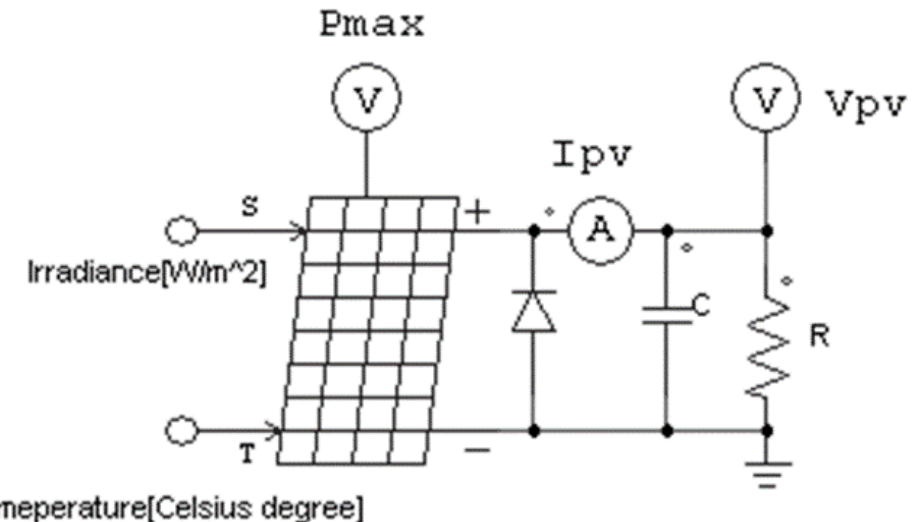

Temeperature[Celsius degree]

(a)

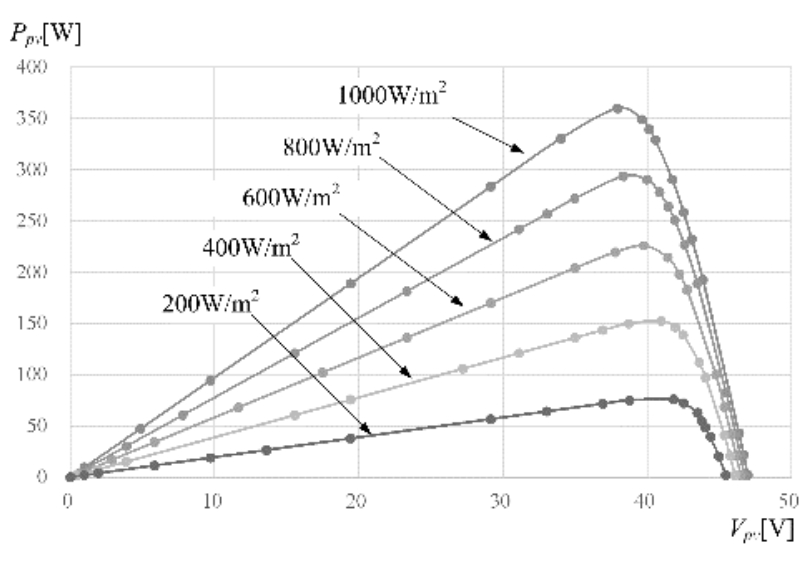

(b)

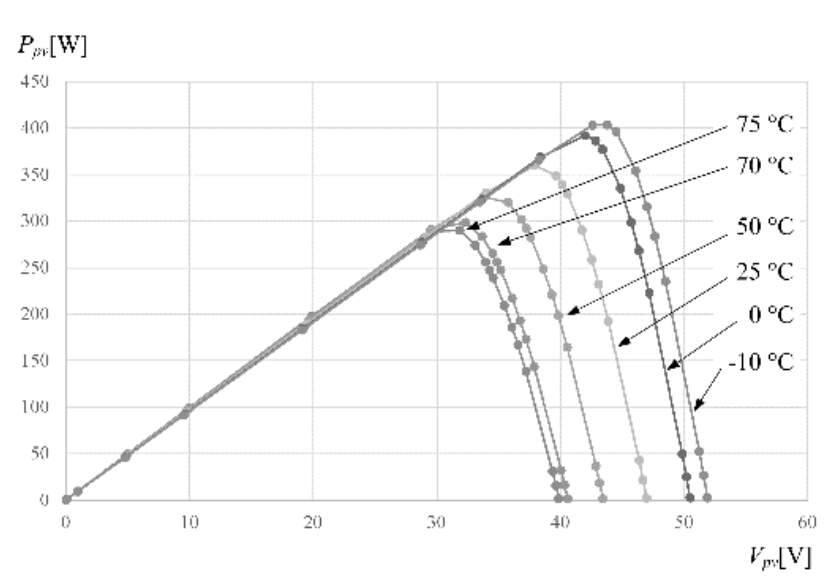

(c)

Figure 1. Simulated PV modeling using a commercial PV module specification. (a) Simulation circuit model, (b) Voltage-power characteristics under varying irradiances, (c) Voltage-power characteristics under varying temperature.

Table 1: Specification of a commercial PV module for the residential PV system

\begin{tabular}{|l|l|}
\hline Parameter & Value \\
\hline Maximum power, $P_{\max }$ & $360[\mathrm{~W}]$ \\
\hline Voltage at maximum power, $V_{m p}$ & $38[\mathrm{~V}]$ \\
\hline Current at maximum power, $I_{m p}$ & $9.47[\mathrm{~A}]$ \\
\hline Open circuit voltage, $V_{o c}$ & $47.0[\mathrm{~V}]$ \\
\hline Short circuit current, $I_{s c}$ & $9.72[\mathrm{~A}]$ \\
\hline
\end{tabular}

\section{SIMULATION RESULTS}

As one of standard test condition, the irradiance level was defined as $1000\left[\mathrm{~W} / \mathrm{m}^{2}\right]$ when there was no shading condition. In addition, shading strength was selected as $500\left[\mathrm{~W} / \mathrm{m}^{2}\right]$ and
$250\left[\mathrm{~W} / \mathrm{m}^{2}\right]$ according to the extent of the shading effect. For generating 2880 [W] residential PV system, 8 PV modules are connected in series. Totally 14 cases for PV shading are considered as shown in Table 2 to generalize PV characteristic curve under different shading strengths and patterns. As reference PV characteristics, Case 0 is defined as the condition that the eight series PV modules have no shading effect at all. Case 1 was defined as a condition in which a shading strength $500\left[\mathrm{~W} / \mathrm{m}^{2}\right]$ occurred on one of eight modules. Cases 2 to 8 show the conditions that shadings are generated only in two PV modules with the same shading strength as $500\left[\mathrm{~W} / \mathrm{m}^{2}\right]$, and the shading patterns of the two modules are different. Cases 9 to 13 show conditions according to the number of PV modules with shading as $500\left[\mathrm{~W} / \mathrm{m}^{2}\right]$. Cases 14 shows the condition under different shading strengths of $500\left[\mathrm{~W} / \mathrm{m}^{2}\right]$ and $250\left[\mathrm{~W} / \mathrm{m}^{2}\right]$ with the same shading pattern of Case 2. 
International Journal of Engineering Research and Technology. ISSN 0974-3154, Volume 13, Number 10 (2020), pp. 2536-2540

(C) International Research Publication House. https://dx.doi.org/10.37624/IJERT/13.10.2020.2536-2540

Table 2: Fourteen cases for shading conditions in the residential PV system

\begin{tabular}{|c|c|c|c|c|c|c|c|c|}
\hline 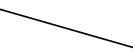 & PV\#1 & PV\#2 & PV\#3 & PV\#4 & PV\#5 & PV\#6 & PV\#7 & PV\#8 \\
\hline Case 0 & $1000\left[\mathrm{~W} / \mathrm{m}^{2}\right]$ & & & & & & & \\
\hline Case 1 & $500\left[\mathrm{~W} / \mathrm{m}^{2}\right]$ & & & & & & & \\
\hline Case 2 & & & & & & & & \\
\hline Case 3 & & & & & & & & \\
\hline Case 4 & & & & & & & & \\
\hline Case 5 & & & & & & & & \\
\hline Case 6 & & & & & & & & \\
\hline Case 7 & & & & & & & & \\
\hline Case 8 & & & & & & & & \\
\hline Case 9 & & & & & & & & \\
\hline Case 10 & & & & & & & & \\
\hline Case 11 & & & & & & & & \\
\hline Case 12 & & & & & & & & \\
\hline Case 13 & & & & & & & & \\
\hline Case 14 & & $250\left[\mathrm{~W} / \mathrm{m}^{2}\right]$ & & & & & & \\
\hline
\end{tabular}

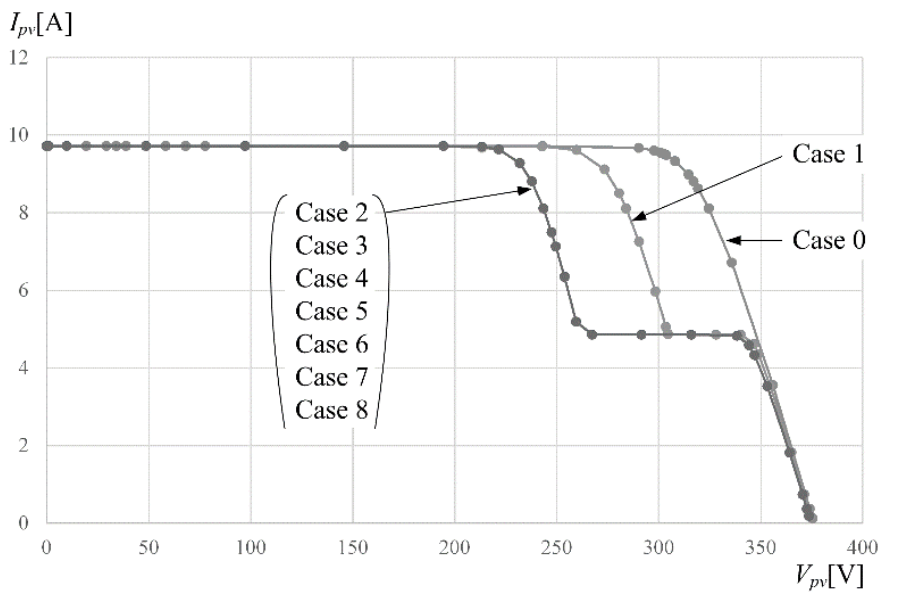

(a)

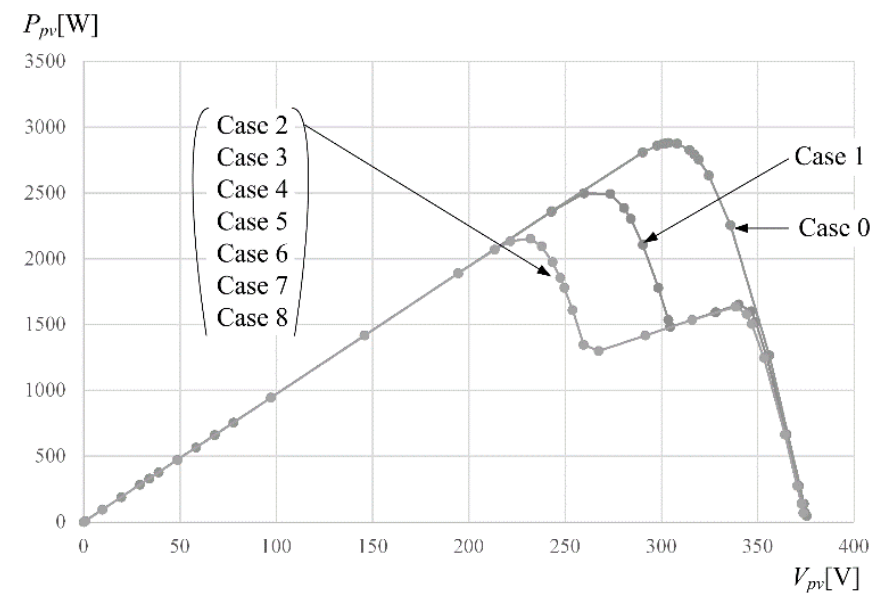

(b)

Figure 2. Simulation results of PV characteristics when the shading patterns are different with two shaded PV modules under the same shading strength $500\left[\mathrm{~W} / \mathrm{m}^{2}\right]$. (a) Voltage-current curve of PV array, (b) Voltage-power curve of PV array

Figure 2 shows PV characteristic curves for case 2 to case 8 , when two PV modules are shaded with the intensity of 500 $\left[\mathrm{W} / \mathrm{m}^{2}\right]$. In addition, Case 0 with no shading at all and Case 1 with $500\left[\mathrm{~W} / \mathrm{m}^{2}\right]$ shading on a single PV module are considered for comparison. Case 0 has one maximum power point, 2879[W], and Case 1 has two maximum power points, 2497[W] and 1602[W] because the shaded PV module in Case 2 generates a different current level than the other PV modules without shading. In comparison, Case 2 to Case 8 has all the same PV characteristics when two PV modules are shaded with different patterns and has two maximum power points, 2153[W] and $1636[\mathrm{~W}]$. This is because there are two different current levels under $1000\left[\mathrm{~W} / \mathrm{m}^{2}\right]$ and $500\left[\mathrm{~W} / \mathrm{m}^{2}\right]$ irradiance. When the number of shaded PV modules with a particular shading strength is the same, the same PV string characteristics are shown even though the shading distribution is different. This is because bypass diodes are attached to PV modules and the total current flowing through the string circuit is not reduced even when the two PV modules are shaded. 


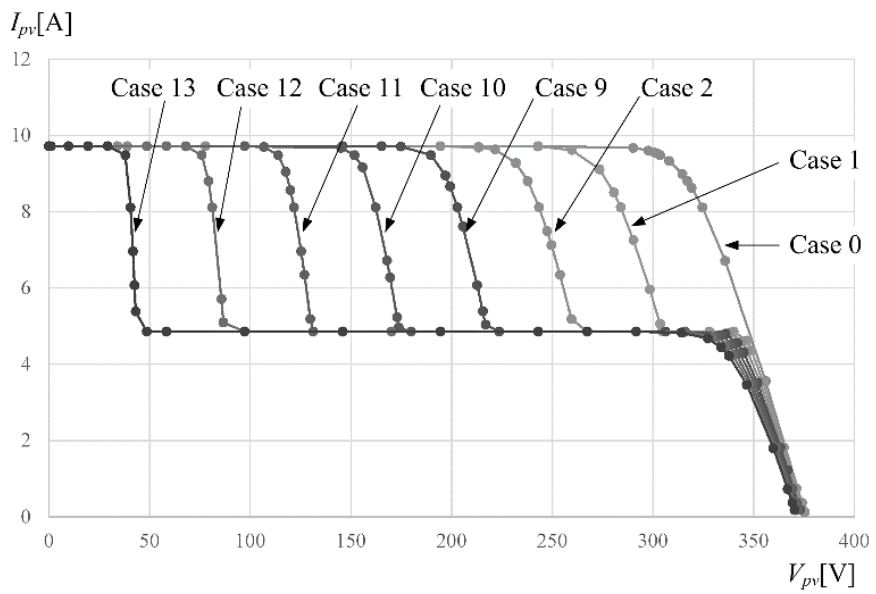

(a)

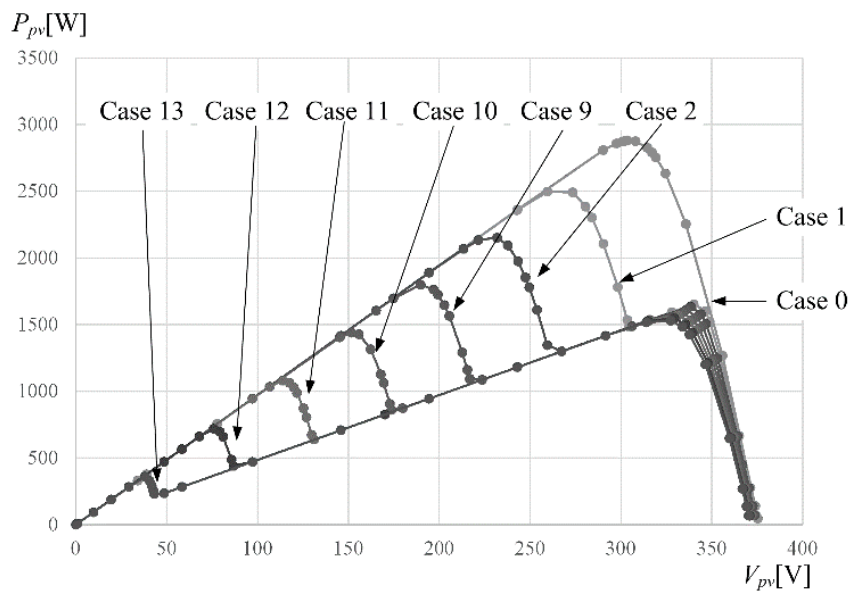

(b)

Figure 3. Simulation results of PV characteristics when the number of shaded PV modules are different with the same shading strength 500[W/m²]. (a) Voltage-current curve of PV array, (b) Voltage-power curve of PV array.

Figure 3 shows PV characteristic curves when the number of shaded PV modules is from 1 to 7 with the same shading strength of $500\left[\mathrm{~W} / \mathrm{m}^{2}\right]$. When shadows occur on the PV modules with the same strength, the maximum power point of $\mathrm{PV}$ characteristics is always 2 regardless of the number of shaded PV modules. This is because there are only two current levels with the current under $500\left[\mathrm{~W} / \mathrm{m}^{2}\right]$ and under $1000\left[\mathrm{~W} / \mathrm{m}^{2}\right]$. In addition, as the number of shaded PV modules increases, the output power value of the maximum power point at a low voltage gradually decreases.

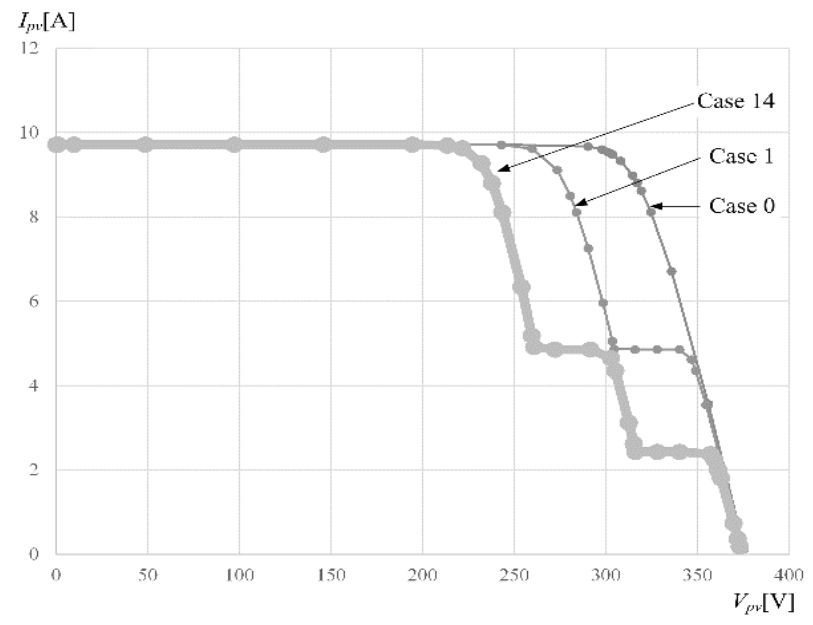

(a)

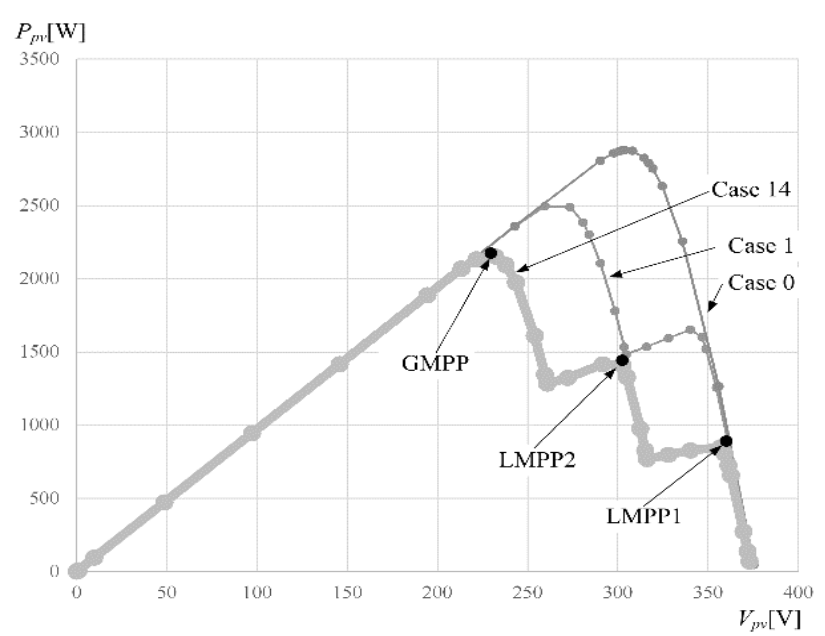

(b)

Figure 4. Simulation results of PV characteristics for Case 14 when the shading strength of two shaded PV modules is different as $500\left[\mathrm{~W} /{ }^{2}\right]$ and $250\left[\mathrm{~W} / \mathrm{m}^{2}\right]$ respectively. (a) Voltage-current curve of PV array, (b) Voltage-power curve of PV array

Figure 4 shows PV characteristic curve for Case 14. Since Cases 14 defines as the condition under different shading strengths of $500\left[\mathrm{~W} / \mathrm{m}^{2}\right]$ and $250\left[\mathrm{~W} / \mathrm{m}^{2}\right]$ with the same shading pattern of Case 2, the generating current levels are based on the irradiance $1000\left[\mathrm{~W} / \mathrm{m}^{2}\right], 500\left[\mathrm{~W} / \mathrm{m}^{2}\right]$, and $250\left[\mathrm{~W} / \mathrm{m}^{2}\right]$. It can be said that the number of maximum power points is determined by the number of shading strengths.

Thus, PV characteristics for Case 14 has three maximum power points as Global Maximum Power Point (GMPP), Local Maximum Power Point1 (LMPP1) and Local Maximum Power
Point2 (LMPP2). According to Figure 4, GMPP is 2153[W], LMPP1 is 1417[W], and LMPP2 is 850[W]. Under such conditions, when PV inverter starts operating at the open circuit voltage $V_{o c}$ with the typical Perturbation and Observation (P\&O) Maximum Power Point Tracking (MPPT) control method, it operates at LMPP1 because the first inflection point by $\mathrm{P} \& \mathrm{O}$ MPPT method is LMPP1 [15-17]. LMPP1 is 39.5\% compared to GMPP. Based on the GMPP point, the optimized MPPT method can be developed for a PV string inverter. It will be discussed in the future research. 


\section{CONCLUSION}

This paper presents analysis of PV characteristics for residential application under partial shading conditions. For verifying the analysis method, eight commercial PV modules are considered in series for residential PV system by using PSIM simulation under shading conditions. When the number of shaded PV modules with a particular shading strength is the same, the same PV string characteristics are shown even though the shading distribution is different. When shadows occur on the PV modules with the same strength, the maximum power point of $\mathrm{PV}$ characteristics is always 2 regardless of the number of shaded PV modules. The number of maximum power points is determined by the number of shading strengths. This generalization of PV characteristics under partial shading can be used to develop the optimal MPPT method and analyzed performance analysis for a residential PV system. In addition, this paper presents the research results on the PV characteristics of PV string for residential use, but as an additional research field, a study to generalize the shading effect on multi-string PV modules for PV commercial or plant use seems to be necessary.

\section{REFERENCES}

[1] W. Jewell, R. Ramakumar, and S Hill, A study of dispersed photovoltaic generation on the PSO system, IEEE Transaction on Energy Conversion, 3(3), 1988, 473-478.

[2] W. Jewell, Electric utility experience with solar photovoltaic generation, IEEE Transactions on Energy Conversion, 4(2), 1989, 166-171.

[3] Z. Wu, Y. Hu, J. Wen, F. Zhou, and X. Ye, A review for solar panel fire accident prevention in large-scale PV applications, IEEE Access, 8, 2020, 132466-132480.

[4] T. Karin and A. Jain, Photovoltaic string sizing using site-specific modeling, IEEE Journal of Photovoltaics, 10(3), 2020, 888-897.

[5] M. Boztepe, F. Guinjoan, G. Velasco-Quesada, S. Silvestre, A. Chouder, and E. Karatepe, Global MPPT scheme for photovoltaic string inverters based on restricted voltage window search algorithm, 61(7), 2014, 3302-3312.

[6] K. Saleh, A. Hooshyar, E. El-Saadany, and H. Zeineldin, Voltage-based protection scheme for faults within utility-scale photovoltaic arrays, IEEE Transactions on Smart Grid, 9(5), 2018, 4367-4382.

[7] J. Ma, H. Jiang, Z. Bi, K. Huang, X. Li, and H. Wen, Maximum power point estimation for photovoltaic strings subjected to partial shading scenarios, 55(2), 2019, 1890-1902.

[8] T. Takashima, Behavior of interconnect-failed PV modules under standard test conditions and actual operation conditions, IEEE Journal of Photovoltaics, 8(6), 2018, 1761-1766.

[9] J. Raj and A. Jeyakumar, A novel maximum power point tracking technique for photovoltaic module based on power plane analysis of I-V characteristics, IEEE Transactions on Industrial Electronics, 61(9), 2014, 4734-4745.

[10] Z. Mao, Z. Sunan, M. Peng, S. Yanlong, and Z. Weiping, Modelling of PV module and its application for partial shading analysis - part I: model and parameter estimation of PV module, The Journal of Engineering, 13, 2017, 1295-1298.

[11] B. Yu and S. Ko, Study on serially connected PV modules under partial shading condition, International Journal of Engineering Research and Technology, 13(1), 2020, 54-57.

[12] H. Ziar, B. Asaei, S. Farhangi, M. Korevaar, O. Isabella, and M. Zeman, Quantification of shading tolerability for photovoltaic modules, IEEE Journal of Photovoltaics, 7(5), 2017, 1390-1399.

[13] P. Bharadwaj and V. John, Subcell Modeling of partially shaded photovoltaic modules, IEEE Transactions on Industry Application, 55(3), 2019, 3046-3054.

[14] J. Ma, X. Pan, K. Man, X. Li, H. Wen, and T. Ting, Detection and assessment of partial shading scenarios on photovoltaic strings, IEEE Transactions on Industry Application 54(6), 2018, 6279-6289.

[15] J. Teng, W. Huang, T. Hsu, and C. Wang, Novel and fast maximum power point tracking for photovoltaic generation, IEEE Transactions on Industrial Electronics, 63(8), 2016, 4955-4966.

[16] N. Kasa, T. Lida, and H. Iwamoto, Maximum power point tracking with capacitor identifier for photovoltaic power system, IEE Proceedings-Electric Power Applications, 147(6), 2000, 497-502.

[17] E. Dallago, A. Liberale, D. Miotti, and G. Venchi, Direct MPPT algorithm for PV sources with only voltage measurements, IEEE Transactions on Power Electronics, 30(12), 2015, 6742-6750. 